Nigerian Veterinary Journal

Vol. 32(I): 20II; 63 - 64

CASE REPORT

\title{
An Unusual Huge Abscess in a Buffalo Bull (Bubalis bubalis): Case Report
}

HUSSEIN, K.H.

Department of Surgery, Faculty of Veterinary Medicine, Assiut University, Assiut, Egypt.

Correspondence: Kamaleldeen.youssif@vet.au.edu.eg Tel: +20109815235

\section{INTRODUCTION}

Abscess is a localized suppurative inflammation limited by a wall of granulation tissue (Sasty and Rama, 2004). One of the most important causes of abscesses in Egyptian buffaloes is the lymphatic borne infection. Oedematous skin disease (OSD) is widely distributed in Egyptian buffaloes and became endemic in Egypt (Selim, 2001). OSD is caused by Corynebacterium pseudotuberculosis and characterized by appearance of circumscribed nodules which gradually developed into closed abscess containing bloody to pus tinged with blood or pure creamy pus along the course of lymphatic vessels of the forelimbs, abdomen, and thigh (Sayed et al., 2007). In this paper, the huge abscess at an atypical site, i.e. lateral to the mandible of a buffalo bull, and its successful treatment by surgical excision is reported.

KEYWORDS: abscess; oedematous skin; corynebacterium; water buffalo.

\section{HISTORY AND CLINICAL SIGNS}

A 1 year old, buffalo bull was admitted to the veterinary teaching hospital, Assiut University, for presence of a large swelling in the size of large water melon lateral to the right branch of mandible and decrease of appetite. The swelling was reported to have been present for more than three months. At presentation, the limbs were edematous and the temperature was $40.5^{\circ} \mathrm{C}$. The animal was treated by a local veterinarian using high dose of penicillin and streptomycin in addition to cortisone which leads to disappearance of the edema from the limbs but the abscess persisted.

On admission, the buffalo bull had thin appearance with normal clinical parameters. There was a large, warm, painful, fluctuating and sharply circumscribed swelling in the size of large melon lateral to the right mandible (Figure 1). Aspiration revealed presence of bloody pus with offensive odor. Ultrasonographic examination revealed presence of hypoechoic area with hyperechoic flakes within the swelling while the thickness of the capsule was $1.6-2 \mathrm{~cm}$ (Figure 2). The radiographic examination revealed presence of radiodense content (Figure 3 ). Sample of the aspirated exudate was sent to the microbiology lab for detection of the causative agent.

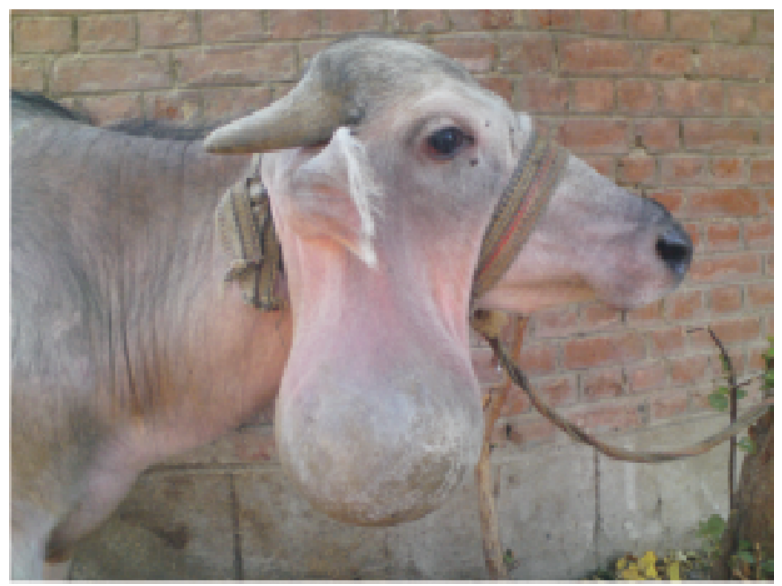

Fig. 1 Large swelling lateral to the mandible

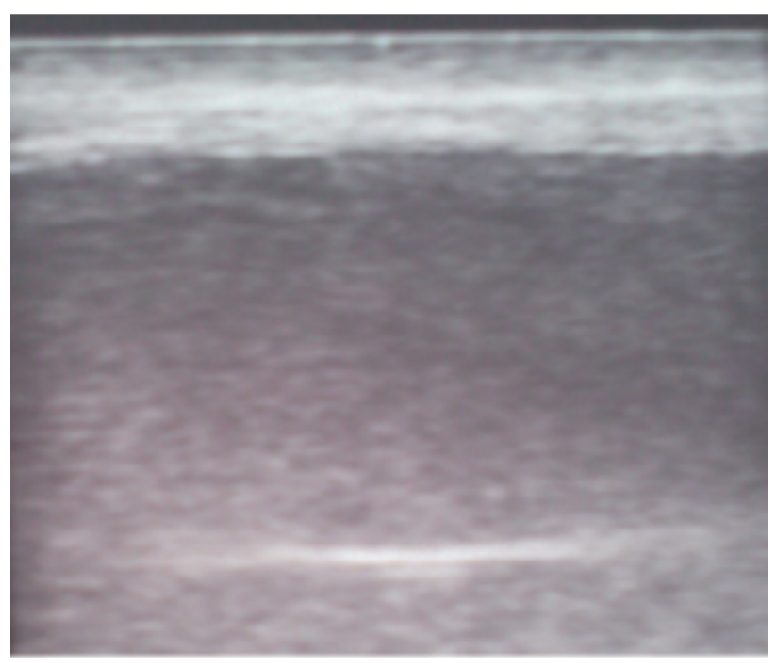

Fig. 2 Ultrasonographic examination showing presence of hypoechoic fluid with hyperechoic flakes of pus in addition to presence of thick capsule 


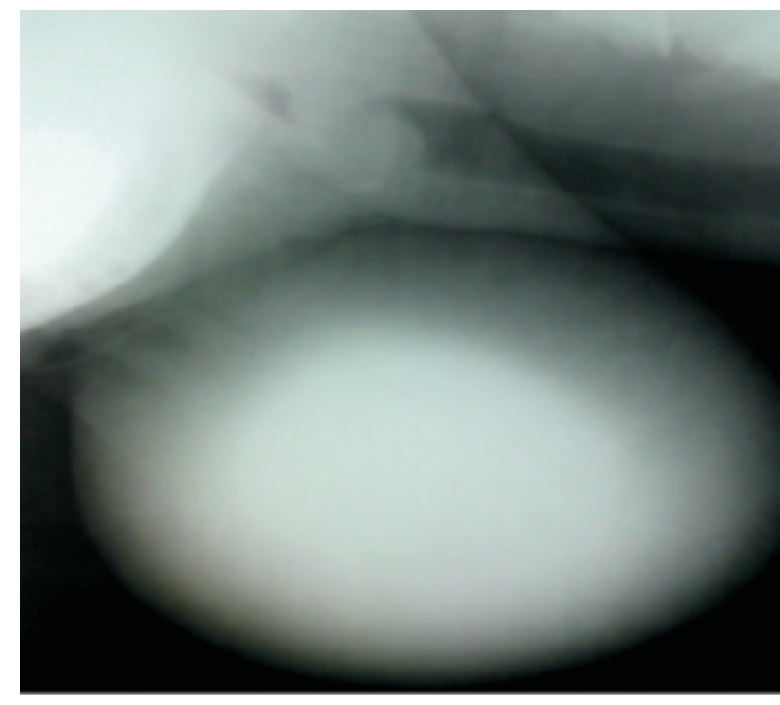

Fig 3. Radiographic film showing presence of radio-opaque content within the swelling \& absence of attachment of the swelling with the surrounding tissues \& bone

\section{MANAGEMENT}

The abscess was removed by surgical excision under the effect of xylazine hydrochloride $(0.1 \mathrm{mg} / \mathrm{Kg})$ and circular infiltration analgesia around the neck of the swelling by lidocaine hydrochloride $2 \%$. The bull was in recumbent position and the surgical area was prepared aseptically. An elliptical incision was performed around the base of the swelling. Blunt dissection was done very slowly and carefully between the skin and the capsule of the closed abscess. The larger blood vessels were doubly ligated and severed while hemostasis of the small blood vessels was done by pressure or crushing using mosquito forceps. The dissection was continued until complete excision of the abscess without opening it. Then the subcutaneous tissue and fascia were sutured with chromic catgut No. 3 in a simple continuous suture pattern. The skin was closed with silk No.2 in a simple interrupted suture pattern. Aqueous solution of penicillin was infiltrated at the site of operation. Postoperatively, ciprofloxacin and corticosteroid were administrated. The skin sutures were removed after 10 days. The physical examination of the bull on the $10^{\text {th }}$ and $30^{\text {th }}$ days postoperatively revealed healthy animal without any postoperative complications. The surgical correction resulted in returning to normal food intake and increasing of body weight. Long-term follow-up obtained four months after surgery revealed a sound bull with good cosmetic appearance.

The weight of the abscess after removal was $5 \mathrm{~kg}$ while the volume of the bloody pus was $4100 \mathrm{ml}$. The diameter of the wall was $1.7 \mathrm{~cm}$ in average. Corynebacterim pseudotuberculosis was cultured from the aspirate.

Buffaloes are highly susceptible than cows to OSD, and more common in age group of 8 months up to 3 years. Insects play a major role in transmission of the disease, so the disease is more prevalent during summer months in Egypt. The disease was diagnosed for first time in April 1960 (El-Sawalhy, 1999). In the present case, recurrence wasn't reported. Total extirpation is possible if the abscess is accessible with a well developed capsule and no surrounding cellulites (Flower, 1998).It can be stated that the ultrasonographic examination offers excellent method for measurement of the abscess capsule and the relationship with the surrounding tissues which help the surgeon in detection of the preferred treatment technique.

\section{REFERENCES}

EL-SAWALHY, A.A. (1999): Veterinary infectious diseases. $2^{\text {nd }}$ edition, ZAFER office, Zagazig, Egypt.

FLOWER, M.E. (1998): Medicine and surgery of South American camelids: Llama, Alpaca, Vicuno, Guanaco. $2^{\text {nd }}$ edition, Iowa State University Press, Iowa, U.S.A.

SASTRY, G.A. AND RAMA, P.R. (2004): Veterinary pathology. $7^{\text {th }}$ edition, Satish Kumar Jain, New Delhi, India.

SAYED, S.M.; RATEB, H.Z.; ARAFA M.I.; ABDEL-HAFEEZ M.M. AND AMER A.A (2007): Field study on buffaloe oedmatous skin disease in Assiut governorate. Assiut Vet.Med.J.53 (114):189-2006.

SELIM, S.A. (2001): Oedmatous skin disease of buffaloe in Egypt. J.Vet. Med. B. 48, 241-258. 